\title{
A questão ecológica na gestão dos corpos hídricos - analisando os focos das diretrizes brasileira e européia.
}

\section{Lafayette Dantas da Luz Maria Teresa Ferreira}

RESUMO: Neste artigo são discutidos os focos considerados para a classificação e definição de metas para a gestão dos corpos d'água nas legislações Brasileira e Européia. Embora no Brasil, na sua Constituição Federal, em Constituições Estaduais, na Lei Nacional de Recursos Hídri$\cos (9433 / 1997)$ e em Resoluçōes diversas encontremos referências a "meio ambiente ecologicamente equilibrado", "desenvolvimento sustentável, baseado nos princípios da função ecológica da propriedade", "equilíbrio ecológico aquático", "meio ambiente ecologicamente equilibrado", dentre outras, verifica-se que os instrumentos reguladores que dão suporte às açôes de gestão apresentam limitaçóes para o trato da questão, devido a serem os "usos da água" o foco central. A condição qualitativa das águas vem secundariamente, em nosso entender, e ainda baseado em indicadores que apenas fornecem uma idéia muito restrita das condições ecológicas. Em contraste, a Diretiva Européia da Água, em curso de implementação pela União Européia, traz uma centralidade, ainda pouco compreendida, que significa uma mudança radical de paradigma na gestão das águas. Seu foco está no "estado ecológico" das massas de água, sendo que os usos da água devem ser condicionados a partir dessa contextualização. Essa inversão de focos é avaliada, a fim de uma reflexão sobre a necessidade de se avançar, no Brasil, em termos da integração da gestão ambiental com a gestấo das suas águas, mesmo diante das dificuldades que a experiência européia tem mostrado para sua efetivação e dos desafios que se apresentam no Brasil para tal.

PALAVRAS-CHAVE: Gestão, recursos hídricos, ecohidrologia, paradigma, Diretiva Européia da Água, legislação
ABSTRACT: This article discusses the focuses that are involved in the classification and definition of initiatives for management of water bodies in the Brazilian and European laws. Although in the Brazilian Federal Constitution, in State's Constitutions, in the National Water Act (9433/1997) and in several Resolutions references to "an ecologically balanced environment", "sustainable development, based on the principles of ecological function of the property", "aquatic ecological balance", and "ecologically balanced environment" can be found, it appears that regulatory instruments that lead to management actions have limitations for dealing with the question, due to the central focus to be on the "uses of the water". The qualitative condition of the water comes second, in our view, and still based on indicators that provide only a very limited idea of ecological conditions. In contrast, the Water Framework Directive, under implementation by the European Union, brings a central focus, yet poorly understood, which means a radical change of paradigm in water management. Such focus relies on the "ecological status" of water bodies, and the uses of the water should be conditioned within that context. This change in focus is analyzed in order to emphasize the need of integrating environmental management and water management in Brazil, despite the difficulties that the European experience has shown for its implementation and the challenges for a similar approach in Brazil as well.

KEY-WORDS: Management, water resources, ecohydrology, paradigm, European Water Framework Directive, legal framework

\section{INTRODUÇÃO}

"The significant problems we face cannot be solved at the same level of thinking we were at when we created them"

\section{Albert Einstein}

A quantidade de mananciais de água doce e seus ecossistemas associados que se encontra em condiçóes degradadas ou tendendo a isso, total ou parcialmente, é significativa e preocupante. Os ecossistemas aquáticos têm sido os de maior perda de biodiversidade o que, conforme Falkenmark (2008), situa-se em cerca de $50 \%$, ocorrida ao longo dos últimos 30 anos. Tal degradação, no que se inclui de forma mais visível a qualidade das águas, se soma à heterogeneidade espacial e temporal da ocorrência e distribuição hídrica para o agravamento do acesso das populaçóes à água. Esses fatos têm conduzido a situaçôes de escassez, em especial em locais mais vulneráveis devido a condiçôes 
físicas limitantes para a produção e armazenamento das águas, bem como em locais onde a concentração da presença humana e/ou de suas atividades econômicas exerce pressão excessiva sobre a disponibilidade hídrica que é limitada (Falkenmark e Widstrand, 1992). Dessa realidade, decorrem conflitos entre usuários ou, ainda, um aumento da pobreza e agravamento da qualidade de vida humana e não-humana. Ainda, considerando o agravamento das alteraçóes climáticas e a não redução das taxas de crescimento populacional, a demanda relativa deve se agravar, especialmente em países "em desenvolvimento", assim como o desafio para países com maior disponibilidade relativa de água não será apenas prover quantidades, mas prover suprimentos com qualidade que minimize problemas de saúde pública (Vorosmarty et al, 2000).

Diante desse quadro, esforços têm sido feitos a fim de mitigar os problemas, sendo evidente a necessidade de uma efetiva gestão do uso dos recursos naturais das bacias hidrográficas, em especial do uso da água. A gestão do uso dos recursos hídricos, nos seus primórdios, era tratada como um problema restrito ao acesso humano à água (por comunidades e por setores econômicos) em termos quantitativos. Historicamente observa-se a predominância de ações de gestão das disponibilidades hídricas (oferta), comumente com a busca e exploração de novos mananciais, e uma despreocupação com seus limites e conseqüências (Falkenmark, 2008). As demandas, por sua vez, tampouco eram questionadas e os esforços situavam-se em atendê-las, situação que atualmente se verifica como necessária de ser também submetida à gestáo (Hespanhol, 2008).

A degradação da qualidade das águas foi observa$\mathrm{da}$, posteriormente, como fator limitante adicional à disponibilidade hídrica, o que requereu protocolos de avaliação e controle qualitativo das águas. Para o primeiro avanço no trato dos recursos hídricos, visando à gestão também da qualidade das águas, procedimentos e parâmetros indicadores foram sendo incorporados nos protocolos de análise e monitoramento. Estes essencialmente referiam-se a aspectos organolépticos (cor, cheiro e gosto) e patogênicos da água. Indicadores microbiológicos, como a presença de bactérias do grupo coliforme, foram precursores em termos da detecção de contaminaçáo biológica. Indicadores físicos e químicos davam conta das condiçôes organolépticas, mas também de salubridade/ potabilidade, dentre eles destacando-se: temperatura, $\mathrm{pH}$, oxigênio dissolvido, demanda bioquímica de oxigênio, nitrogênio e fósforo totais, resíduos e turbidez. Diante dos efeitos de poluição generalizada, inclusive por novas substâncias sintéticas, legislaçóes têm estendido enormemente as listagens de parâmetros necessários de serem monitorados. Adicionalmente, em funçáo do desconhecimento de muitos poluentes e ainda mais dos potenciais efeitos sinérgicos que podem ocorrer entre os mesmos no ambiente, outras técnicas de monitoramento têm sido adotadas, a exemplo da qualidade biológica da água (Hellawell, 1996), da integridade biótica das comunidades aquáticas (Karr, 1991), da saúde do ecossistema (Karr e Dudley, 1981; Calow, 1992; Pollard e Huxham, 1998; Norris e Thoms, 1999), ou da integridade ecológica (Pollard e Huxham, 1998) ou ambiental (O'Keeffe et al, 2007), dentre outras designaçóes com alguma similaridade. A primeira delas faz uso direto de ensaios ecotoxicológicos e uso de bioindicadores, os biomarcadores, os quais são respostas dos sistemas vivos a agentes estressores, mensurados em nível bioquímico, celular, fisiológico ou comportamental (Nascimento, 2002; Nascimento et al, 2006). Estas abordagens visam identificar condições que exprimam uma síntese dos inúmeros fatores intervenientes na qualidade do ambiente e que separadamente pouco dizem sobre o todo.

Lentamente e não de forma homogênea e generalizada, a gestão das águas tem avançado de uma abordagem quali-quantitativa, centrada nos usos humanos, para uma visão mais ampla que considera os mananciais associados às bacias que os geram e os mantém e que, ainda mais, sustentam ecossistemas dos quais a humanidade faz parte. Os sistemas de gerenciamento dos recursos hídricos, e das águas, vêm incorporando em seus estatutos e diretivas essa compreensão mais ampla do problema, mas ainda guardam os traços das determinantes históricas e regionais.

Particularidades de cada espaço regional, nacional ou pan-nacional devem ser tomadas em conta e incorporadas aos seus sistemas de gerenciamento. No entanto, há aspectos conceituais que resultam de um processo histórico de experiência e aprendizado e que podem ser generalizados tanto quanto as condições específicas das conjunturas sociais, econômicas, políticas, culturais e científicas permitam. Nessa linha, vemos nas experiências brasileira e européia uma oportunidade para reflexão sobre os seus estágios no trato da questão. Se os sistemas de gerenciamento não devem ser rigorosamente iguais, podem ainda avançar mais ao se valer de experiências, conceitos e paradigmas que atualmente diferem, mas que 
podem ser adaptados e incorporados. Esse aspecto é avaliado adiante à luz da legislação brasileira e dos elementos essenciais da Diretiva Européia da Água, dando-se destaque a como a dimensão ecológica é efetivamente tratada nesses marcos regulatórios, a sua importância e as possibilidades para sua adoção de forma mais efetiva.

\section{A DIMENSÃO AMBIENTAL E ECOLÓGICA NO SISTEMA BRASILEIRO DE GESTÃO DOS RECURSOS HÍDRICOS}

A questão ambiental no Brasil teve especial relevância a partir da realização da Conferência RIO 92, a qual foi um marco importante para a disseminação da discussão sobre o conceito de sustentabilidade e sua aplicabilidade, além das questóes ambientais ganharem mais espaço e açôes para além daquelas dos ativistas ambientais. Mesmo antes desse evento o reconhecimento da necessidade de se tratar as condiçóes ambientais sustentavelmente já conseguia extrapolar, no Brasil, as rodas ambientalistas e acadêmicas, atingindo a esfera política, o que foi refletido na Constituição Federal de 1988, durante o processo de redemocratização do país.

No que tange as águas, a Constituição deu suporte ao que seria refletido anos após na "Lei Nacional dos recursos Hídricos" (9433/97), quanto à dominialidade e descentralização administrativa para a gestão das águas, definindo bacias hidrográficas e rios em federais e estaduais, mas em especial quanto ao caráter de "bem público e de uso comum" das águas. Em seu Art. 225, do Capítulo VI referente ao Meio Ambiente, é postulado que: “...todos têm direito ao meio ambiente ecologicamente equilibrado, bem de uso comum do povo e essencial à sadia qualidade de vida, impondo-se ao Poder Público e à coletividade o dever de defendê-lo e preservá-lo para as presentes e futuras geraçôes" (Brasil, 2010a. Grifo nosso.).

A Lei Federal 9433/97 (Brasil, 2010b) estabeleceu a política e o Sistema Nacional de Gerenciamento de Recursos Hídricos (SNGRH) definindo os instrumentos para sua implementação: "(I) os Planos de Recursos Hídricos; (II) o enquadramento dos corpos de água em classes; (III) a outorga dos direitos de uso de recursos hídricos; (IV) a cobrança pelo uso de recursos hídricos; (V) o Sistema de Informaçóes sobre Recursos Hídricos".

Visando uma gestão das águas com caráter participativo e integrado, os Comitês de Bacias Hidrográficas são considerados a base para tal, sendo constituídos por colegiados instituídos por Lei, no âmbito do SNGRH e dos Sistemas Estaduais. Têm papel deliberativo e são compostos por representantes do Poder Público, da sociedade civil e de usuários da água, podendo ser instalados oficialmente em águas de domínio da União e dos Estados, regulamentados por legislação específica nos âmbitos federal e dos estados da União.

Dos instrumentos para implementação da Política Nacional dos recursos hídricos (PNRH), indica-se sucintamente a seguir os seus objetivos primordiais, no entanto, adiante, são apenas feitos resgates dos aspectos conceituais dos mesmos no que se referem ao trato da questão ambiental e ecológica. Os Planos diretores visam "fundamentar e orientar a implementação da Política Nacional de Recursos Hídricos e o gerenciamento dos recursos hídricos". O Enquadramento dos corpos de água em classes, segundo os usos preponderantes da água, visa: “(I) assegurar às águas qualidade compatível com os usos mais exigentes a que forem destinadas; (II) diminuir os custos de combate à poluição das águas, mediante açôes preventivas permanentes" (grifos nossos). A Outorga visa "assegurar o controle quantitativo e qualitativo dos usos da água e o efetivo exercício dos direitos de acesso à água”. A Cobrança pelo uso da água tem como objetivo: "(I) reconhecer a água como bem econômico e dar ao usuário uma indicação de seu real valor; (II) incentivar a racionalização do uso da água; (III) obter recursos financeiros para o financiamento dos programas e intervenções contemplados nos planos de recursos hídricos" (grifos nossos). O Sistema de Informações sobre Recursos Hídricos visa a "coleta, tratamento, armazenamento e recuperação de informaçóes sobre recursos hídricos e fatores intervenientes em sua gestão" (Brasil, 2010b).

Referindo-se ao principal mecanismo a tratar da condição de qualidade dos corpos de água, o Enquadramento, verifica-se a menção direta e central aos "usos" mais importantes ou evidentes para estabelecer o seu sistema de classificação. A qualidade do corpo hídrico está subordinada, conforme o seu item I, aos usos a que o mesmo venha atender. A Outorga, por sua vez, se refere ao "controle ... qualitativo dos usos da água”, o que diz respeito ao potencial poluidor ou degradador da atividade usuária, além de mencionar os "direitos de acesso à água", pautando-se com isso sobre as necessidades humanas e econômicas, somente. Por outro lado, o instrumento Cobrança, em seu item II, objetiva indicar aos usuários (pessoas ou organizaçóes) o "real valor" da água, o faz em base 
"econômica" (item I), o que pode ser entendido como base "monetária", em termos práticos. Afinal, não se trata de "valor" enquanto categoria subjetiva de julgamento e percepção da realidade.

Tratando dessas três diretivas apenas, verifica-se a total priorização do uso humano para fins econômicos como orientação às açóes que visam atender aos objetivos da PNRH, assim como uma grande lacuna quanto aos aspectos ecológicos associados ao uso do recurso natural água, demonstrando assim uma forte concepção utilitarista: "(I) assegurar à atual e às futuras geraçóes a necessária disponibilidade de água, em padróes de qualidade adequados aos respectivos usos; (II) a utilização racional e integrada dos recursos hídricos, incluindo o transporte aquaviário, com vistas ao desenvolvimento sustentável; (III) a prevenção e a defesa contra eventos hidrológicos críticos de origem natural ou decorrentes do uso inadequado dos recursos naturais".

No que tange os Planos Diretores de Recursos Hídricos, os mesmos em geral têm se pautado no diagnóstico de disponibilidade hídrica, assim como na identificação dos usos atuais e potenciais, e no máximo contemplando as possibilidades de uso integrado e alguma restrição referente às condiçóes qualitativas das águas. Novamente, nesse instrumento, os usos humanos têm sido centrais, sendo que as questóes ecológicas restringem-se à afirmação da importância de áreas de preservação e unidades de conservação.

Neste artigo é feita maior referência ao instrumento Enquadramento dos corpos de água devido a nele residir, em sua regulamentação legal, a Resolução 357/2005 do Conselho Nacional de Meio Ambiente - CONAMA (Brasil, 2010c), atualizada pela Resolução 430/2011, as diretrizes ambientais para a classificação das massas de água doce, salobras e salinas. No preâmbulo dessa Resolução embora sejam feitas mençôes a que "a água integra as preocupaçôes do desenvolvimento sustentável, baseado nos princípios da função ecológica da propriedade", dentre outros princípios, e "no reconhecimento de valor intrínseco à natureza"; assim como "que a saúde e o bem-estar humano, bem como o equilíbrio ecológico aquático, não devem ser afetados pela deterioraçáo da qualidade das águas"; e também "que o controle da poluição está diretamente relacionado com a proteção da saúde, garantia do meio ambiente ecologicamente equilibrado e a melhoria da qualidade de vida", observa-se no decorrer de seu texto a constante subordinaçáo da classificação dos corpos de água e da definição de metas aos usos humanos atuais ou esperados, expressamente apresentados como "usos preponderantes".

Ainda no preâmbulo, há referência à classificação das águas doces, salobras e salinas, como sendo "essencial à defesa de seus níveis de qualidade, avaliados por condiçóes e padróes específicos, de modo a assegurar seus usos preponderantes. No Capítulo I, Das Definiçóes, a "classe de qualidade" assim como "classificaçáo" são associadas claramente ao atendimento dos usos preponderantes. Similarmente, quando define "enquadramento", o coloca como meta ou objetivo de qualidade da água (classe) a ser "alcançado ou mantido em um segmento de corpo de água, de acordo com os usos preponderantes pretendidos, ao longo do tempo". Algumas concessóes são feitas com relação à biota como no caso da referência aos limites individuais para cada substância considerados em cada classe (Art. $7^{\circ}$.), quando trata de eventuais interaçôes entre tais substâncias, as quais "não poderão conferir às águas características capazes de causar efeitos letais ou alteração de comportamento, reprodução ou fisiologia da vida". Porém volta a salientar que: "bem como de restringir os usos preponderantes previstos". Assim, mistura os propósitos, reportando-se a diferentes aspectos, mas sem hierarquizá-los claramente. Nas diretrizes ambientais para o enquadramento (Capítulo V) é indicado que "o enquadramento do corpo hídrico será definido pelos usos preponderantes mais

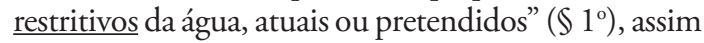
como "nas bacias hidrográficas em que a condição de qualidade dos corpos de água esteja em desacordo com os usos preponderantes pretendidos, deverão ser estabelecidas metas obrigatórias, intermediárias e final, de melhoria da qualidade da água” $\left(\$ 2^{\circ}\right)$.

Soma-se a essa clara subordinação do trato da qualidade das massas de água aos usos, o fato dos indicadores da qualidade da água restringirem-se a parâmetros físicos, químicos e bacteriológicos, muito embora alguma referência seja feita ao "equilíbrio ecológico aquático". Não são considerados parâmetros baseados em indicadores biológicos, com os quais se espera que expressem e sejam síntese das condiçôes ambientais (Simon, 2003). Também, não são considerados processos ambientais ou biológicos, o fluxo e balanço de energia, a condiçáo de produtividade, a estrutura e funçóes dos ecossistemas, ou outros aspectos que pudessem fornecer uma avaliação mais efetiva do estado das massas de água. Ou seja, a dimensão ecológica dos corpos hídricos não é considerada e avaliada no processo de Enquadramento, o que é ratificado por Oliveira e Marques (2008). 
Embora se trate de um aspecto adicional, convém salientar que o Enquadramento ao não fazer qualquer menção aos aspectos quantitativos das águas, ou seja, a valores das descargas ou ao regime hidrológico, dissocia um processo que é extremamente importante para a qualidade das águas. Nesse contexto deveriam ser considerados regimes hídricos que potencializem processos ecológicos e ambientais (vazóes ambientais), a fim de aumentar as chances de garantia da qualidade desejada para as águas (Acreman e Ferguson, 2010).

Ao se enfatizar essas questóes, deseja-se chamar a atenção para outras experiências em que há uma mudança de foco. A Diretiva Européia da Água é uma referência que merece ser analisada quanto aos seus fundamentos conceituais, o que é apresentado no item a seguir.

\section{A DIMENSÃO AMBIENTAL E ECOLÓGICA NA DIRETIVA EUROPÉIA DA ÁGUA (Water Framework Directive)}

A Uniāo Européia aprovou no ano 2000 o Sistema de Diretivas para a Água - Water Framework Directive (JOCE, 2000), um bem estruturado e estratégico sistema visando orientar e lidar com a condiçáo dos corpos hídricos europeus, assumindo o objetivo de estes virem a atingir um "bom estado ecológico" até o ano de 2015 (Alves et al, 2002).

Dentre os principais aspectos introduzidos pela Diretiva destacam-se (INAG, 2010): abordagem integrada de proteção das águas (de superfície e subterrâneas); avaliaçáo do estado das águas através de uma abordagem ecológica; planejamento integrado em nível da bacia hidrográfica; Planos de Gestão de Bacia incluindo programas de medidas; estratégia para a eliminação da poluição causada por substâncias perigosas; instrumentos financeiros; incremento da divulgação da informação e incentivo da participação do público; organização do quadro legal comunitário.

Restringindo-nos ao aspecto principal que se deseja destacar neste artigo, a abordagem ecológica para a avaliação do estado das águas, a Diretiva considera "qualidade ecológica das águas" como uma expressão da estrutura e funcionamento das comunidades biológicas, porém levando também em consideração fatores naturais fisiográficos, geográficos e climáticos, condiçôes físicas e químicas das águas, e também impactos que resultam das atividades humanas. Essa avaliação da qualidade ecológica dos corpos hídricos superficiais, os quais são vistos como ecossistemas aquáticos, é medida pelo desvio entre a situação exis- tente e aquela que existiria na ausência de intervenção humana, sendo desenvolvida independentemente dos usos atuais ou potenciais praticados nessas águas (Alves et al, 2002). São estabelecidas metas a serem cumpridas pelos países membros da Uniâo Européia (UE) em médio e longo prazo, bem como puniçóes aos que não cumprirem as determinações, além de ter sido instituído um fundo destinado à amortização dos custos de implementação das políticas hídricas.

Essencialmente, para a implementação da Diretiva e, logo, o cumprimento dos objetivos ambientais determinados, se faz necessário o desenvolvimento e a aplicação por parte dos Estados-membros dos princípios, orientaçóes e medidas diversas, relacionadas à definição do "estado ecológico", destacando-se as seguintes (Pio e Henriques, 2000):

Definição da tipologia dos meios hídricos: rios, lagos, águas de transição, águas costeiras, meios hídricos fortemente impactados e meios hídricos artificiais. Vale-se de dois Sistemas, A e $\mathrm{B}$, com variantes nos aspectos considerados para a classificação, enquadrando as bacias hidrográficas em ecorregióes. Ambos os sistemas incluem fatores obrigatórios: altitude, dimensão da área de drenagem e geologia. Adicionalmente, o sistema B prevê como fatores obrigatórios a latitude e a longitude e, como fatores facultativos, a distância à nascente, energia do escoamento, largura e profundidade média dos escoamentos, declive médio do escoamento, configuraçáo do leito principal do rio, categoria do caudal (escoamento) fluvial, forma do vale, transporte sólido, capacidade de neutralização dos ácidos, composição média do substrato, cloretos, amplitude térmica média do ar, temperatura média do ar e precipitação. A seleção do sistema a adotar fica a cargo de cada Estado-Membro, podendo ainda ser considerados outros elementos (Alves et al, 2002, 2006).

Definição das condições ecológicas de referência: para cada tipo de massa de água (e.g., rios de montanha graníticos) são identificados locais de baixa influência humana, onde são amostradas as comunidades biológicas existentes e a estrutura hidrogeomorfológica e analisado o regime natural de vazóes, resultando em parâmetros utilizados como referência. Nos locais de mesma tipologia, são comparados os mesmos parâmetros (químicos, físicos e biológicos) e avaliado o seu grau de desvio com 
relação às condições referenciais. Para todos os parâmetros usados deve ser demonstrada a sua reação significativa às pressóes humanas. Em função da longa história de impactos antrópicos sobre os territórios europeus, as condiçôes de referência têm sido reportadas a evidências das condições pré Era Industrial (até o século XVIII ou meados do XIX, conforme o local), já que é praticamente impossível e pouco realista se remontar a condiçôes 'naturais', no sentido de anteriormente às ocupaçóes e açóes humanas mais intensas (Nijboer et al, 2004). No caso dos meios hídricos "artificiais" (e.g., canais) ou fortemente modificados (e.g., rios urbanos e rios represados), os elementos de qualidade buscam estabelecer o "máximo potencial ecológico", devendo corresponder aos utilizados para a categoria de meio hídrico "natural" que mais se assemelhe.

Desenvolvimento de sistemas de avaliação dos elementos de qualidade ambiental: cinco níveis de classificação qualitativos do estado ecológico sáo definidos pelos diferentes graus das alteraçóes causados pela atividade humana sobre os elementos de qualidade. O estado ecológico pode variar de "Excelente" a "Mau" conforme os efeitos da atividade humana sejam identificados como de "Mínimos" a "Muito Graves".

Estabelecimento de programas de monitoramento: visa a avaliação do estado das águas, classificando-as e apresentando os resultados (monitoramento de vigilância) e o diagnóstico de problemas e acompanhamento dos programas de medidas aplicados (monitoramento operacional). Complementarmente a essas, o monitoramento de investigação poderá ser implementado a fim de obter informaçôes requeridas para novos conhecimentos e estudos. Cada Estado-membro define sítios de monitoramento que constituirão a denominada "rede de intercalibração".

Harmonização dos métodos de monitoramento em nível nacional para as condiçóes de referência. A aplicação das categorias para os diferentes níveis de estado ecológico pode ser susceptível a interpretaçóes subjetivas, além de referirem-se a avaliações desenvolvidas com base em elementos de monitoramento e metodologias diferenciadas entre os Estados-membros. Com isso um processo denominado de "inter-calibração" é efetuado, harmonizando os indicadores de qualidade e permitindo que as sançôes comunitárias devido a não cumprimentos sejam semelhantes para todos os países por comparabilidade de resultados.

Aplicação e apresentação da classificação do estado ecológico em nível Comunitário (CEE), a partir dos dados nacionais.

No processo de definição do "estado ecológico" são avaliadas também as condiçóes dos corpos hídricos resultantes das pressóes exercidas pelas atividades humanas em termos de seu tipo e de sua magnitude. Estas são verificadas especialmente em termos da qualidade da água e das alteraçóes hidromorfológicas. Destaca-se a identificação e avaliação das fontes significativas de poluentes, pontuais e difusas, com origem urbana, industrial, agrícola ou outras, o que é orientado por Diretivas específicas. As classificaçōes finais do "estado ecológico" são definidas pelo pior dos resultados de monitoramento dos elementos indicadores da qualidade biológica, física e química. Saliente-se que para as águas subterrâneas aplica-se o mesmo princípio (da obtenção do bom estado ecológico), mas utilizando apenas parâmetros químicos para medir o desvio entre as condiçóes do aquífero com degradação da qualidade (por exemplo, concentração de nitratos) frente à condição sem influência humana. Também, as referências à proteção das águas subterrâneas são frequentemente abordadas quanto aos riscos aos sistemas superficiais dependentes das mesmas (Pio et al, 2000; Acreman e Ferguson, 2010).

A Diretiva da União Europeia não se refere explicitamente a regime ou vazóes ambientais, mas exige que os Estados membros alcancem uma condição de bom estado ecológico em todas as massas de água, o que é avaliado por referência à biologia aquática. Indiretamente, pressupóe-se que regimes hidrológicos ecologicamente adequados são necessários para cumprir tal estado e possibilitar a restauração dos ecossistemas fluviais (Acreman e Ferguson, 2010).

No seu Artigo $13^{\circ}$ a Diretiva da Água se refere aos Planos de Gestão de Bacias Hidrográficas. Trata da circunscrição das bacias e, logo, da abrangência dos Planos frente aos limites políticos entre os países; refere-se a eventuais necessidades de programas e planos de gestão mais pormenorizados, em nível de sub-bacia, setor, problema, ou tipo de água, dedicados a aspectos específicos da gestão das águas; dos prazos para publicação e revisão; e remete ao Anexo VII quanto às informaçóes que os mesmo deverão conter. Essas informaçóes compreendem: características da região, 
incluindo ecorregiôes, tipos de massas de água e condiçôes de referência (ecológica) das mesmas; descrição das pressóes e impactos significativos da atividade humana sobre o estado das águas (conseqüência de usos e intervençôes); identificação e localização das zonas protegidas; as redes de monitoramento; uma lista dos objetivos ambientais; resumo da análise econômica das utilizaçóes da água; resumo de medidas diversas (referentes a objetivos ambientais e programas, principalmente); registro de quaisquer programas e planos de gestão relativos à região hidrográfica que tratem de sub-bacias, setores, problemas ou tipos de águas; resumo das medidas de consulta e informação ao público que tenham sido tomadas; lista das autoridades competentes; os contatos e os procedimentos necessários para a obtenção das informaçóes e dos documentos de apoio e em especial dados relativos às medidas de controle adotadas e dados de monitoramento.

Isso posto, observa-se que as condiçóes, ou estados, ambientais e ecológicos das massas de água e das bacias são o foco dos artigos da Diretiva, incluindo o conteúdo dos Planos de Bacias. Visando a identificação de causas dos estados diagnosticados, há referência aos usos da água, intervençóes estruturais nas bacias e corpos de água e às fontes de poluição. Assim, verifica-se uma diferença de foco e delineamento das diretrizes Européias, onde os usos são vistos como causa das condiçóes das massas de água e um "melhor estado" é o objetivo para as mesmas.

Ressalte-se que os usos humanos não deverão necessariamente ser restringidos a partir dessa abordagem. Deverão, no entanto, estar sendo considerados de forma a manter os mananciais em bom estado, ou deverão esses ser submetidos a programas que visem à recuperação da sua qualidade ou compensar a perda desta. Observa-se que as situaçóes onde os impactos são irreversíveis ou cujos custos para recuperação sejam "desproporcionados" (e.g., em casos de massas de água fortemente alteradas), estes mananciais passam a ser qualificados por seu "potencial ecológico" e não mais pelo seu "estado ecológico", dando coerência a açôes que visarão melhorias dentro das condiçôes de restrição impostas pela realidade.

\section{A MUDANÇA DE FOCO - IMPORTÂNCIA E VIABILIDADE}

\section{Por que a ,dimensão ecológica deve ser considerada}

O conceito de ecossistema tem sido levado gradualmente para o campo das políticas públicas e metodo- logias empregadas no gerenciamento de rios (Thoms e Sheldon, 2002), como é o caso da Diretiva Européia da Água a qual colocou a ecologia aquática como base das decisóes da gestão das águas (Hering et al, 2010). As abordagens tradicionais no gerenciamento das águas pautavam-se, ou ainda se pautam, em procedimentos que exprimem as concepçóes vigentes sobre a forma e o grau de conexão das atividades humanas com os ambientes. Assim, normalmente se verificam intervençóes fortemente baseadas em grandes investimentos de capital, fortemente dependentes em tecnologia e projetos de engenharia ("hidro-tecnologia”) e uso intensivo dos recursos naturais. Construção de barragens, estruturas para captação e adução a longas distâncias, transposiçóes de água entre bacias, controle de cheias, sistemas de irrigação e drenagem em perímetros agrícolas, sistemas de tratamento de esgotos e efluentes, são alguns exemplos de estruturas prioritárias e essenciais nessa forma de gerenciamentos dos recursos hídricos (Harper et al, 2008; Hespanhol, 2008). Essencialmente trata-se de transformar e ajustar a natureza, os ambientes ou os processos às necessidades dos usos humanos, ao invés de ajustar nossas atividades às condiçóes que os ambientes proporcionam. Essa tem sido a essência da Engenharia dos Recursos Hídricos, quando novos desenvolvimentos e açóes intensivas tecnologicamente proporcionariam sempre a solução para novas questóes que viessem a se apresentar.

No entanto percebe-se, após décadas dessas práticas, que em geral tais intervençóes ou deterioraram condições ambientais ou são altamente consumidoras de energia e capital, dessa forma náo se enquadrando no que se espera como soluçóes sustentáveis. Tal forma de condução, se não ignora os impactos ao ambiente e aos ecossistemas que daquelas intervençôes resultam, baseia-se, em muitos casos, em avaliaçóes que apenas parcialmente conseguem identificar elementos de qualidade do ambiente. Assim é que foi incorporada a análise de parâmetros físicos e químicos das águas, por exemplo, a fim de se inferir a qualidade das águas. Mas, ainda, voltando-se apenas para os riscos que a condição de qualidade analisada poderia trazer para dado uso humano. Definem-se, entáo, padróes aceitáveis para tais ou quais usos, visando reduzir os riscos para a saúde humana (e.g. efeitos patogênicos ou de toxidez), para o funcionamento da infraestrutura (e.g. grau de corrosão de estruturas metálicas), para o processamento da água em termos de custos e dificuldades de tratamento (e.g. devido à eutrofização) ou outros. Em termos das políticas de 
gestão das águas, estas têm se pautado basicamente na definição de padrôes de qualidade para os usos, no controle da emissáo de efluentes e na tentativa de minimizar ou mitigar os impactos das pressôes antropogênicas sobre a qualidade das águas (Hering et al, 2010). Outras formas de avaliação das condiçóes dos corpos de água passaram a ser vistas como necessárias. As análises toxicológicas foram um progresso nesse sentido, ao lado da utilização de bioindicadores sensíveis a alteraçóes ambientais, o que proporcionou novas perspectivas no sentido da compreensão da qualidade dos corpos de água, entendidos como ecossistemas e não somente como mananciais para abastecimento. Tais procedimentos e abordagens buscam identificar condiçóes que a análise de parâmetros físicos e químicos por si só não detectam ou permitem, o que significou um avanço em termos de abordagem ecológica.

Conforme Pio e Henriques (2000), a adoção do conceito de "qualidade ecológica" surgiu, na Comunidade Européia, pela necessidade de se ter um quadro de avaliação da qualidade da água mais abrangente, pois as águas de superfície se mantinham com níveis relativamente elevados de poluição, mesmo depois de todas as medidas tomadas por força da aplicação da legislação em vigor à época, referente à proteção das águas.

A própria deterioração da qualidade das águas, no entanto, em muitos casos resulta de causas pouco ou não perceptíveis a partir das análises de parâmetros físicos e químicos. Ainda mais complexa é a situação se o objetivo for a inferência dos danos aos ecossistemas, comunidades ou populaçóes específicas, enfim as perdas de biodiversidade, já que apresentam causas múltiplas e combinadas, o que torna praticamente impossível a detecção de estressores ou fatores causais únicos. Variações climáticas, fontes difusas de contaminação, contaminaçóes episódicas ou cumulativas e alteraçóes físicas do meio hídrico, em zonas ripárias e/ ou na bacia, não apresentam efeitos imediatos, além de se combinarem, constituindo assim algumas das causas que justificam a necessidade de uma abordagem diferenciada para uma melhor compreensão da situaçáo dos corpos de água e um gerenciamento mais efetivo das águas, inclusive estas como recurso.

A partir das condiçôes físico-climáticas das bacias estabelecem-se os ecossistemas, num processo de metabolismo permanente, perseguindo estados de equilíbrio dinâmico de sua homeostase. As condiçóes vigentes de um ecossistema ou as suas condiçóes ecológicas resultam, então, de uma combinação de fatores que se expressam em escalas espaciais e temporais múltiplas, sendo síntese de múltiplos fatores ambientais, incluindo as intervençôes humanas. Sendo síntese, a "condição ecológica" de um ecossistema, se bem identificada, e mesmo sendo dinâmica, se constitui numa forma poderosa de avaliação da qualidade ambiental e de aferir o potencial de sustentabilidade de nossas ações.

Mas porque proteger ecossistemas? Ou porque buscar uma boa condição ecológica para os mesmos? $\mathrm{Ou}$, simplesmente, porque considerar a "condição ecológica” (ou o "potencial ecológico", como previsto na Diretiva Européia da Água para sistemas hídricos fortemente alterados) como o indicador global, apropriado para balizar o gerenciamento dos corpos de água e dos recursos hídricos?

A primeira razão é o aspecto de "síntese" que a "condiçáo ecológica" possibilita, de diversos fatores abióticos e bióticos condicionando, no espaço e no tempo, os processos e inter-relaçóes ambientais e ecológicas que resultam num "estado" do ecossistema, e nisso se inclui a qualidade e a quantidade (forma e regime de ocorrência) das águas.

Adicionalmente, os ecossistemas em boa condição nos oferecem uma gama de serviços ecológicos que muitas vezes não são reconhecidos claramente pelo público. Os serviços mais facilmente reconhecíveis, e menos controversos (Cairns, 1996), são aqueles aos quais valores econômicos são visivelmente atribuíveis. Este é o caso, por exemplo, do poder de auto-purificação das águas, provimento de alimento, combustível e outros recursos pelos ecossistemas. Em casos como esses os valores econômicos são facilmente incorporáveis às tomadas de decisão. Os benefícios de outros serviços ecológicos nem sempre são tão perceptíveis como, por exemplo, a preservação da dada(s) espécie(s), ou da biodiversidade, o que decorre da limitação do conhecimento humano e de aspectos culturais.

O chamado "uso passivo" ou mesmo o "não-uso" de certos bens e serviços proporcionados pela natureza tem sido considerado em análises econômicas. Algumas dessas abordagens são: o Valor de Opção, referente a preservar ou manter um bem natural visando à opção de uso futuro; o Valor de Existência, com o qual se assume que dado bem natural tem um valor independentemente de seu uso; Valor Altruístico de Existência, baseado no desejo ou possibilidade de outros virem a usar o bem; e o Valor de Legado, com o qual o altruísmo é dirigido para as próximas geraçóes, as quais poderão se beneficiar da preservação e manutenção de um bem natural. O campo da Eco- 
nomia Ecológica tem desenvolvido procedimentos de valoração para essas categorias (Costanza 1989, 1996). Embora estes procedimentos nem sempre sejam plenamente aceitos, sem tal valoração os serviços ecológicos são usualmente desconsiderados como externalidades (Cairns, 1996).

A proteção dos ecossistemas tem sido frequentemente associada à necessidade de manutenção das funçóes biológicas e hidrológicas, contemplando produção de alimento e energia, manutenção de habitats e da resiliência - "o seguro contra colapso" (Falkenmark, 2008). A autora, no entanto, afirma que o gestor de recursos hídricos necessita informação mais específica a fim de determinar que componentes do ambiente devam ser considerados cruciais para proteção. Isso deve ser definido com base em análises diagnósticas que identifiquem os problemas-chave ecológicos na bacia, as causas da degradaçáo e as cadeias causais envolvidas. Para uma abordagem dessa forma, é requerida atenção adequada às relaçóes entre hidrologia e ecologia, o que entấo deveria guiar as açóes de gestáo.
Zalewski et al (1997) apresentam e discutem o termo "Ecohidrologia" como área multidisciplinar de conhecimento e como conceito a ser adotado para uma transição da ecologia descritiva, da conservação restritiva e da gestáo essencialmente baseada na engenharia tradicional para uma fase operacional criativa, com planejamento preditivo e uso sustentável dos ecossistemas aquáticos. Essa transição é esquematizada na Figura 1.

\section{As dificuldades da nova abordagem com base na experiência européia}

Certamente que se tal abordagem tem um forte apelo, mostrando conteúdo e consistência, por outro lado trata-se de novos passos numa direção em que não faltam dificuldades e incertezas. Algumas destas podem ser presumíveis, no entanto é possível se valer de experiências como a implementação da Diretiva, em que pesem especificidades regionais e nacionais, socioeconômicas e culturais.

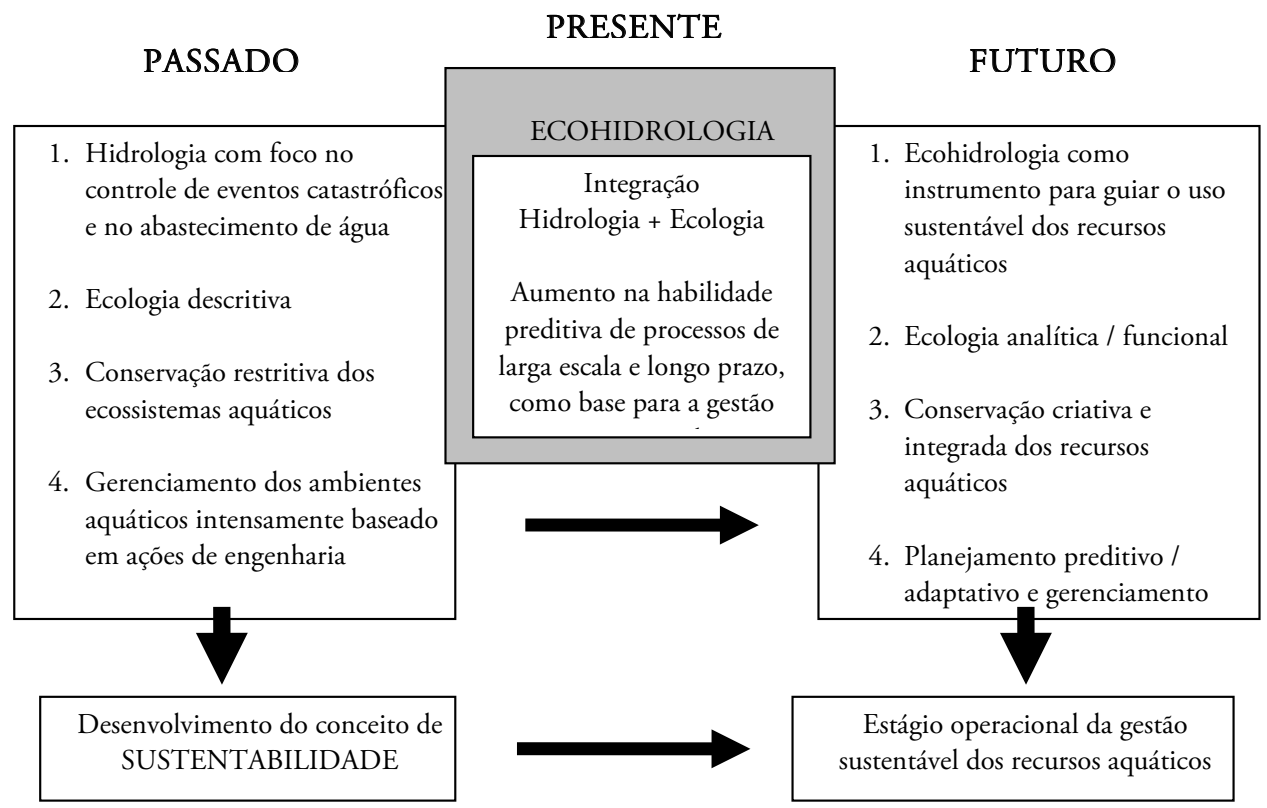

Figura 1 - Transição entre concepções e práticas no rumo de uma gestão dos corpos de água ecologicamente baseada; a ecohidrologia como abordagem fundamentadora (adaptado de Zalewski et al, 1997) 
Hering et al (2010) fazem um balanço crítico da implementação da Diretiva Européia da Água ao longo dos últimos dez anos. Embora reafirmem que o aspecto mais inovador da Diretiva esteja em basear as decisóes dos gestores nos efeitos dos estressores sobre o ecossistema ao invés de enfocar sobre o próprio estressor (e.g. poluição), o grande desafio está em como traduzir dados de comunidades biológicas em informaçôes para medidas de restauração, assim como de avaliaçốes ecológicas em decisóes de gestão. Essa interface entre o gerenciamento das águas e a manutenção do ecossistema aquático representa, sem dúvida, uma dificuldade e um desafio para os gestores, (Postel, 1996, Jackson et al, 2001; Newson e Large, 2006). Ainda, Hering et al (2010) destacam o papel extremamente positivo desse processo de implementação da Diretiva, afirmando que um dos maiores avanços referentes ao sistema de avaliação em curso está no uso de diversos indicadores de qualidade ecológica e na consideração de tipologias para os corpos de água. A diversidade de tipologias, entretanto, não permite o uso de métodos simples, em menor número e amplos o suficiente para amostragem e avaliação em toda a Europa. Também, as tradições de biomonitoramento diferem entre os países membros, com o que tem havido um atraso no processo devido ao lento desenvolvimento de sistemas de avaliação por muitos daqueles países. A partir disso, porém, tem ocorrido um melhor entendimento da ecologia aquática graças a essa necessidade de desenvolvimento de métodos de avaliação. É observado, no entanto, o fato das incertezas que persistem nas avaliaçóes. Discutem desde a necessidade de que os esquemas de amostragem venham a ser melhorados, assim como seus métodos de análise. Isso remete para a necessidade de formação de pessoal capacitado, assim como questionam a capacitação das agências de proteção ambiental com relação ao entendimento da necessidade da base científica. Destacam ainda como positivo o envolvimento de grupos diversos da sociedade nesse processo: cientistas, técnicos, gestores das águas, usuários e políticos. Ressaltam também, que os gestores temem que os resultados da intercalibração venham a alterar significantemente os passos já tomados na implementação da Diretiva com base nos primeiros planos de bacia, especificamente quanto a quais corpos de água podem ser identificados como necessários de ser restaurados.

\section{Alguns desafios para adoção de tal abordagem no Brasil}

A adoção, no Brasil, de uma base diferenciada para a gestão das águas centrada na compreensão e avalia- ção ecológica dos ecossistemas aquáticos, conforme o que vem sendo exposto neste texto, certamente exige uma mudança bastante profunda. Mesmo com as bases atuais, diversos mecanismos previstos para integrar o sistema de gestão dos recursos hídricos estão ainda por ser praticados. Se por um lado isso mostra um estado inicial de desenvolvimento, com suas dificuldades inerentes, por outro possibilita a discussão e o ajuste de condutas, dado não haver ainda práticas totalmente arraigadas.

Certo é que modelos não devem ser importados, desconsiderando a realidade local. No entanto a experiência européia apresenta traços que podem ser avaliados criticamente frente à realidade brasileira e podem representar avanço se devidamente considerados.

Devido a sua dimensão continental e à grande variação geomorfológica e climática, o Brasil abriga sete biomas e 49 ecorregióes (delimitadas usando critérios abióticos e bióticos - fitogeográficos e zoogeográficos associados a grupos de mamíferos, aves, répteis e anfíbios), conforme classificação do Ministério do Meio Ambiente / IBAMA, e incalculáveis ecossistemas. A diversidade de sua fauna e flora é imensa, representando um grau de dificuldade bastante grande para a avaliaçáo ecológica se utilizados métodos de análise de países de regióes temperadas onde a estrutura das comunidades e ecossistemas pode ser menos extensa. A rede hidrométrica nacional em algumas regióes e bacias pode limitar quantificaçôes mais precisas e confiáveis, às vezes estando aquém da densidade recomendada pela Organização Mundial de Meteorologia. Some-se a isso a grande lacuna em informaçóes ecológicas básicas o que requereria um imenso investimento em pesquisa. Os rios tropicais apresentam uma dinâmica que difere daqueles cursos d'água que deram origem a muitas teorias e modelos ecológicos de sistemas fluviais. O Conceito de Pulsos de Cheias (Junk et al, 1989), por exemplo, é um modelo que melhor explica as dinâmicas ocorrentes em grandes rios tropicais. Nestes casos, também exemplificando, o Conceito de Rio Contínuo (Vannote, 1980), que em muito fundamenta a literatura referente à ecologia de rios, falha em alguns de seus pressupostos frente a particularidades dos rios tropicais (Statzner e Higler, 1985) e rios de grande porte (Sedell et al, 1989). Similarmente, para outras tipologias de cursos d'água brasileiras há necessidade de uma melhor compreensão de seus processos para que seja possível o avanço no sentido de sua efetiva 
preservação ou recuperação dentro de um processo de gestâo das águas.

Em que pese a situação acima mencionada, adicionalmente, e talvez de maior desafio, seja a mudança cultural necessária ao meio técnico e, ainda mais, ao nível político. Tal distância entre a compreensão nos diferentes meios de atuação da sociedade não é exclusividade brasileira, mas traduz o grau de desenvolvimento sócio-político-cultural vigente. Em países mais avançados sócio-economicamente é perceptível a maior sensibilidade no meio político às contribuiçôes apresentadas pela comunidade científica.

\section{CONCLUSÃO}

Nos itens anteriores foram discutidos alguns aspectos das bases regulatórias brasileira e européia no campo da gestão das águas, mais especificamente quanto ao que baliza a conservação ou recuperação da qualidade dos corpos hídricos. Buscou-se ressaltar a ênfase que é dada em tais diretrizes, no caso brasileiro colocando os usos da água como condicionadores da classificação e metas a serem definidas para os corpos de água, enquanto no caso europeu a condição ecológica identificada é confrontada com uma condição de referência (desejável) e, com isso, definidas as metas de melhoria e determinadas as condiçóes de uso das águas que não comprometam tais metas. Este último caso trata-se de um processo em construção e sujeito a dificuldades diversas, mas que já apresenta ganhos significativos conforme registram muitos cientistas e praticantes. No Brasil, por sua vez, ainda se busca implementar um sistema de gestão das águas que, mesmo sem o foco ecológico da Diretiva européia, ainda esbarra em diversos problemas. Também em consolidação no Brasil, encontram-se a política e a gestão ambientais. Na medida em que haja uma efeti- va integração com a política e gestão das águas, como é previsto nas diretrizes da Lei $9433 / 97$, possibilitaria uma mudança de postura e procedimentos para um enfoque ecocên trico, assim condicionando os usos da água. Por situar-se ainda em evolução, visualizamos o seu potencial para ser repensado e aprimorado. Se há entraves de diversas ordens, o aspecto cultural nos parece ser o mais complexo, porém o mais necessário de ser trabalhado. A pouca sensibilidade ou mesmo a relutância para questôes ambientais primárias nas esferas do poder (ou da gestão) e em setores da sociedade e da economia, muito em função da visão utilitarista e imediatista do capital (por investidores e gestores), antecipa as inegáveis dificuldades que se pode prever num processo de mudança de paradigma no trato da gestấo das águas.

No entanto cabe alertar que a necessidade de tal mudança é justificada pela pertinência estratégica e pela potencial eficácia das açóes de gestáo quanto aos aspectos da conservação da qualidade daqueles ambientes. Por sua vez, cabe àqueles que a propóe o aprofundamento da discussão a respeito da necessidade da centralidade ecológica como base para a gestão do uso das águas. Também, a identificação dos mecanismos necessários e das oportunidades que tal mudança pode trazer à sociedade deve estar presente nessa agenda. As questóes ambientais e a centralidade ecológica como critério primário não devem ser vistas como entrave ao desenvolvimento, este concebido como evolução positiva, mas podem representar, sim, restriçốes a relaçóes predatórias com o meio ambiente.

\section{AGRADECIMENTOS}

Agradecemos ao CNPQ pelo apoio ao pesquisador via bolsa de pós-doutorado no exterior.

\section{Referências}

ACREMAN, M.C.; FERGUSON, A.J.D. 2010. Environmental flows and the European Water Framework Directive. Freshwater Biology, vol. 55, p.32-48.

ALVES, M.H.; BERNARDO, J.M.; FIGUEIREDO, H.D.; MARTINS, J. P.; PÁDUA, J.; PINTO, P.; RAFAEL, M. T. 2002. Directiva-Quadro da Água: Tipologias de rios segundo o Sistema $A$ e o Sistema $B$ em Portugal. Actas del III Congreso Ibérico sobre Gestión y Planification del Agua. La Directiva-Marco da Água: realidades y futuros. Fundación Nueva Cultura del Agua. Sevilha, 13 a 17 de Novembro de 2002, p.347-354.

ALVES, M.H.; JBERNARDO, J.M.; CORTES, R.V.; FEIO, M.J.; FERREIRA, J.; FERREIRA, M.T.; FIGUEIREDO, H.; FORMIGO, N.; ILHÉU, M.; MORAIS, M.; PÁDUA, J.; PINTO, P.; RAFAEL, T. 2006. Tipologia de rios em Portugal Continental no âmbito da Directiva Quadro da Água. Actas do $8^{\circ}$ Congresso da Água. 13 a 17 de Março de 2006, Figueira da Foz, Portugal, APRH.

BRASIL. 2010a. CONSTITUIÇÃO DAREPÚBLICAFEDERATIVADO BRASIL DE 1988. Disponível em: http://www.planalto.gov.br/ccivil 03/ constituicao/constitui\%C3\%A7ao.htm. Acesso em 05/07/ 2010. 
2010b. LEI No 9.433, DE 8 DE JANEIRO DE 1997. Disponivel em: http://www.planalto.gov.br/ccivil 03/Leis/L9433.htm. Acesso em: 05 jul. 2010.

2010c. RESOLUÇÃO no 357, DE 17/03/2005. Conselho Nacional de Meio Ambiente (CONAMA). Disp. em: http://www.mma.gov. br/port/conama/res/res05/res35705.pdf. Acesso em 05 jul. 2010.

CAIRNS, J, Jr. 1996. Determining the Balance Between Technological and Ecosystem Services. In: Schulze, Peter (ed.). Engineering Within Ecological Constraints. National Academy of Engineering. 1996. Disponivel em: http://www.nap.edu/catalog/4919.html.

CALOW, P., 1992. Can ecosystems be healthy? Critical considerations of concepts. Journal of Ecosystem Health, 1:1-5.

COSTANZA, R. 1989. What is ecological economics? Ecological Economics, vol. 1, p. 1-7.

COSTANZA, R. 1996. Designing Sustainable Ecological Economic Systems. In: Schulze, Peter (ed.). Engineering Within Ecological Constraints. National Academy of Engineering. 1996. Disponivel em: http://www.nap.edu/catalog/4919.html.

JOCE. 2000. DIRECTIVA 2000/60/CE DO PARLAMENTO EUROPEU E DO CONSELHO, de 23 de Outubro de 2000, que estabelece um quadro de acção comunitária no domínio da política da água. Portugal. L327/1-72. 22/12/2000. (Disponível em: http://dqa.inag.pt)

2006. DIRECTIVA 2006/118/CE DO PARLAMENTO EUROPEU E DO CONSELHO, de 12 de Dezembro de 2006, relativa à protecção das águas subterrâneas contra a poluição e a deterioração. Jornal Oficial das Comunidades Européias. Portugal. L372/19. 27/12/2006. (Disponivel em: http://dqa.inag.pt)

FALKENMARK, M.; WIDSTRAND, C. 1992. Population and water resources: a delicate balance. Popul. Bull. 1992/Nov; vol. 47(3), p.1-36. Disponivel em: http://www.ncbi.nlm.nih.gov/pubmed/12344701. Acesso em: 21/06/2010.

FALKENMARK, M. 2008. Water and Sustainability: A Reappraisal. Environment - Science and policy for a sustainable development. March/April 2008. Disponivel em: http://www.environmentmagazine.org/Archives/Back\%20lssues/March-April\%202008/Falkenmark-full. html. Acesso em: 29/07/2010.

HARPER, David; ZALEWSKI, Maciej; PACINI, Nic. (Eds.) 2008. Ecohydrology : processes, models and case studies : an approach to the sustainable management of water resources. CAB International.

HELLAWELL, J.M. 1996. The contribution of biological and chemical techniques to the assessment of water quality. Em P.J. Boon \& D.L. Howell (eds.) Freshwater quality: defining the indefinable? , pp.89-101. Scottish Natural Heritage. The Stationery Office, Edinburgh.

HERING, D.; BORJA, A.; CARSTENSEN, J.; CARVALHO, L.; ELLIOT, M.; FELD, C.K.; HEISKANEN, A-S.; JOHNSON, R.K.; MOE, J; PONT, D.; SOLHEIM, A.L.; van de BUND, W. 2010. The European Water Framework Directive at the age of 10: A critical review of the achievements with recommendations for the future. Sci Total Environ (2010), doi:10.1016/j.scitotenv.2010.05.031.

HESPANHOL, Ivanildo. 2008. Um novo paradigma para a gestão de recursos hidricos. Estudos Avançados, vol. 22 (63), p.131-58. IEA/USP. INAG. 2010. Ministério do Ambiente e do Ordenamento do Território. Directiva Quadro da Água. Em: http://dqa.inag.pt/index.html. Acesso em 10/06/2010.

JACKSON, R.B.; CARPENTER, S.R.; DAHM, C.N.; MCKNIGHT, D.M.; NAIMAN, R.J.; POSTEL, S.L.; RUNNING, S.W. 2001. Water in a changing world. Ecological Applications, vol. 11, p.1027-1045.

JUNK, W.J.; BAYLEY, P.B.; SPARKS, R.E. 1989. The flood-pulse concept in river-floodplain systems. Em D.P. Dodge (ed.) Proceedings of the International Large Rivers Symposium, p.110-127. Canadian Fisheries and Aquatic Sciences - Special Publication, 106.

KARR, J.R.; DUDLEY, D.R. 1981. Ecological perspectives on water quality goals. Environmental Management, 5:55-68.

KARR, J.R. 1991. Biological integrity: a long-negleted aspect of water resources management. Ecological Applications, 1:66-84.

NASCIMENTO, I.A. 2002. Técnicas de coleta, preservação e preparo de amostras líquidas e de sedimentos para testes de toxicidade. In: Métodos em Ecotoxicidade Marinha: Aplicações no Brasil. Cap. II. São Paulo. Editora Artes Gráficas e Indústria Ltda. 262 p.

NASCIMENTO, I.A.; PEREIRA, S.A.; LEITE, M.B.N.L. 2006. Biomarcadores como instrumentos preventivos de poluição. In Ecotoxicologia Aquática, Princípios e Aplicações. Cap. 17, p.421-432. Editora RIMA, São Carlos, SP.

NEWSON, M.D.; LARGE, A.R.G. 2006. 'Natural' rivers, 'hydromorphological quality' and river restoration: a challenging new agenda for applied fluvial geomorphology. Earth Surface Processes and Landforms, vol. 31, p.1606-1624.

NIJBOER, R. C.; JOHNSON, R. K.; VERDONSCHOT, P. F. M.; SOMMERHAUSER, M.; BUFFAGNI,A. 2004. Establishing reference conditions for European streams. Hydrobiologia, vol. 516, p. 91-105.

NORRIS, R.H.; THOMS, M.C. 1999. River Health. Freshwater Biology, 41, p.194-479. Oxford.

O'KEEFFE, J.; LENS, P.; van STEVENINCK, E. de R.; DOUVEN, W.; van DAM, A.; van der STEEN, P. 2007. In: The environmental integrity of freshwater resources. Water for a changing world - Developing local knowledge and capacity. Alaerts \& Dickinson (eds). Taylor \& Francis Group. London.

OLIVEIRA, C. C.; MARQUES, D da M. 2008. Proteção e Qualidade dos Recursos Hídricos Brasileiros: Contribuições da Diretiva Européia Para a Água. Revista de gestão da Água da América Latina - REGA, Vol.5, n.1. ABRH.

PIO, S.; HENRIQUES, A.G. 2000. O Estado Ecológico Como Critério Para a Gestão Sustentável das Águas de Superfície. Congresso da Água. Portugal, 2000. APRH.

PIO, S.; WEST, C.A.; HENRIQUES, A.G. 2000. Protecção das Águas de Superfície Contra a Poluição por Substâncias Perigosas no Âmbito da Directiva-Quadro da Água. Congresso da Água. Portugal, 2000. APRH. 
POLLARD, P.; HUXHAM, M. 1998. The European Water Framework Directiv: a new era in the management of aquatic ecosystem health? Aquatic Conserv: Mar. Freshw. Ecosyst. vol.8, p.773-792.

POSTEL, S.L. 1996. Dividing the Waters: Food Security, Ecosystem Health, and the New Politics Of Scarcity. Worldwatch Institute: Washington, D.C.

SEDELL, J.R.; RICHEY, J.E.; SWANSON, F.J. 1989. The river continuum concept: A basis for the expected ecosystem behavior of very large rivers?, p. 49-55. In: D.P. Dodge (ed.), Proceedings of the International Large River Symposium. Can. Spec. Publ. Fish. Aquat. Sci. 106.

SIMON, T. P. (ed.). 2003. Biological Response Signatures: Indicator Patterns Using Aquatic Communities, Boca Raton, Florida: CRC Press. STATZNER, B.; HIGLER, B. 1985. Questions and comments on the River Continuum Concept. Canadian Journal of fisheries and aquatic science, v. 42, p.1038-1044.

THOMS, M.C.; SHELDON, F. 2002. An ecosystem approach for determining environmental water allocations in Australian dryland river systems: the role of geomorphology. Geomorphology, v.47, p.153-168.

VANNOTE, R.L., MINSHALL, G.W.; CUMMINS, K.W.; SEDELL, R.; CUSHING, C.E. 1980. The river continuum concept. Canadian Journal of Fisheries and Aquatic Sciences, vol.37, p.130-137.

VOROSMARTY, C.J.; GREEN, P; SALISBURY, J.; LAMMERS, R.B. 2000. Global Water Resources: Vulnerability from Climate Change and Population Growth. Science, vol. 289, July/2000.

ZALEWSKI, M. ; JANAUER, G. A. ; JOLÁNKAI, G. (Eds.) 1997. Ecohydrology. ANew Paradigm for the Sustainable Use of Aquatic Resources. International Hydrological Programme. SC-97/WS/12. UNESCO, Paris.

Lafayette Dantas da Luz Universidade Federal da Bahia, Escola Politécnica, Departamento de Engenharia Ambiental. Brasil.1luz@ufba.br; lluz.ufba@ gmail.com

Maria Teresa Ferreira Instituto Superior de Agronomia, Universidade Técnica de Lisboa. Portugal. marteres@netvisao.pt; terferreira@isa.utl.pt. 